\title{
DESCRIPTION OF A SET OE SIX BLAST ENGINES MADE FOR THE EAST INDIAN IRON COMPANY.
}

In accordance with the request of the Council, that each member should communicate to the Institution the particulars of any work of a novel character in which he may have been engaged, and that would be likely to prove interesting or useful to the members, the following description of a number of Blast Engines that have been recently made for blowing the furnaces of the East Indian Iron Company has been prepared by the writer; and as so many of our friends are engaged in the production of that one metal, which not only exceeds any other in 
usefulness, but all the others put together, it is presumed, that if the construction of these engines is approved, this paper will be of some service.

These engines were made to the plans and under the superintendence of Mr. Charles May, the consulting engineer to the East Indian Iron Company, by Messrs. James Watt and Co., to the drawings prepared by the author of this paper.

The engines are six in number, two pairs of them being intended to blow air at 2 lbs. per square inch as a maximum pressure, and the other pair to blow air at $4 \mathrm{lbs}$. per square inch as a maximum pressure.

Fig. 1, Plate 26, is a side elevation of the engine complete, with crank-shaft, wheels, \&c.

Fig. 2, Plate 27, is a vertical section through the steam and air cylinders, and their valres and passages, and the branch air pipes.

Fig. 3, Plate 28, is a plan, and Fig. 4 shows a sectional plan taken through the air valve, and the air passages and branch air pipes.

The two diagrams, Figs. 5 and 6, Plate 29, show the proportionate size of an ordinary blast engine and one of these engines to the same scale.

There are also indicator figures, Figs. 7, 8, and 9, taken from the air cylinder of an ordinary blast engine and the steam and air cylinders of the new engines.

The general form and construction of the engine is that of a "Pedestal or Table Engine;" the air cylinder $\Lambda$ stands on a short pedestal, and itself forms the pedestal or table on which the steam cylinder $B$ stands. The foundation plate is 6 feet square, and carries a wrought-iron crank shaft $\mathrm{C}$ in four plummer blocks, having two light fly wheels DD, one on each end of the shaft, and the two eccentrics EE for driving the air valve $\mathrm{F}$, one ou each side of the air cylinder, and the eccentric $G$ for driving the steam valve $H$, in the centre. The steam piston has one piston rod fixed in a short cross head $I$ at the top, and this cross head has two other piston rods for driving the air piston, which pass down outside the steam cylinder through stuffing-boxes in the eover of the air cylinder, and are attached to the air piston. The long cross head $K$, taking the connecting rods to the cranks, is attached to the short cross head by a pin, so as to allow a little freedom 
in case of unequal wear; the guides LL are attached to the steam cylinder cover.

The air valve $\mathrm{F}$ is made under Mr. Archibald Slate's patent, and is a ring or crown valve entirely enclosing the air cylinder, and is not selfacting by the pressure of the air in any way, but is moved by the pair of eccentrics $\mathrm{EE}$ at the proper times, so as to give ample passage for the air to move with the greatest freedom, and the valve has such a proportion of lap as to cause the air to be compressed up to the working pressure before it is delivered, thus giving the engine no more work to do than is necessary.

The openings or passages for the air from the air cylinder to the valve are extremely short, and the bars between the openings are made inclined, so as to cause a regular wear on the brass packing rings which form the rubbing face of the valve. The body of the air valve is made of thin sheet iron, neatly curved to two turned cast-iron rings, to which it is well secured by a great number of small bolts; these rings are bored out inside to receive the brass packing rings before mentioned, which are secured in their places by bolts. There are no springs to the brass packing rings, but they are bored out to be a perfect fit to the outside of the air cylinder, and are then cut into eight pieces, and should any wear take place they can be at once adjusted by introducing a thin sheet of paper behind them and screwing them fast in their places again. It should, however, be remarked that this valve is under totally different circumstances from any that have hitherto been made, as it is perfectly in balance, or rather it is suspended perfectly freely, and slides up and down a turned cylindrical surface, and therefore there is no tendency or power to cause wear under any variation in the pressure of the air. The mode in which the two eccentrics drive the air valve is by means of a "Gymbal Ring;" that is to say, there is a wrougbt-iron ring encircling the air valve and attached to it by two pins opposite each other, and the eccentric rods are attached to the ring at two other points at right angles with the first : thus the air valve is perfectly free.

The air cylinder $A$ is 30 in. diameter and $2 \mathrm{ft} .6$ in. stroke, and the piston makes 80 strokes per minute. The air piston is packed with hemp packing, and has a ring to screw it down; the screws are so arranged that they can be got at by simply unscrewing small plugs in 
the cylinder cover, when a socket spanner can be introduced to screw the ring down. The air passes into the air cylinder beyond the end of the valve, first at one end and then at the other, and is delivered into the hollow part of the valve, from which it escapes through two light copper branch pipes MM, placed opposite each other, and having turned joints fitting turned collars fixed on the valve. The other ends of the pipes rest on a small surface or shelf prepared for them, and on which they slide backwards and forwards about $\frac{1}{8}$ th inch; these ends of the pipes are curved in the same manner as the other ends, so that the faces are in one plane, and the air main has the faces of its branches surfaced to receive them, as shown in the plan, Fig. 3 ; thus the air is taken equally from each side of the air valve.

The steam valve $H$ has considerable lap, and is so proportioned as to cut off the steam just after the half stroke and have a very freo exhaust.

The boilers are on the Cornish plan, and will be chiefly used with wood as fuel, and the furnaces are made proportionately large for this purpose. The boilers are fed by a donkey engine entirely jndependent of the blast engines, so that they are complete in themselves, and there is no fear of getting short of water whilst the blast engines stand for "tapping," at which time indeed the boiler should always be fed, if only to keep the steam down a little.

The engines having to be transported some distance up the country, a limit of weight was given, viz., 1 ton for any one part of the engine; and in accordance with this limitation the total weight of a pair of these engines is only 11 tons as compared with 25 tons, the weight of an ordinary blast engine of equal power; and the weight of the heaviest single piece of an ordinary engine is $4 \frac{1}{2}$ tons as compared with 1 ton, the weight of the heaviest piece in the new engines. It is therefore evident that the engine can be moved with the greatest facility, and the first pair put to work here for trial simply stood on some balks of timber, and a few small bolts through the bed plates were sufficient to hold them and cause them to work quite steadily; whereas for the ordinary engine a strong building with massive foundations has to be erected. 
The method by which a high speed for blast engines has been attained is simply that of moving the air valves for the air, having of course very large valves and passages, instead of letting the air itself move the valves. This arrangement, which was introduced by Mr. Slate to this Institution at the Meeting in July, 1850, at once prevents all blow and jar in the working, provided that the lap and lead of the valve are properly proportioned, and allows of the piston being driven at a high velocity, and consequently its diameter may be reduced and its stroke shortened. This mode of working, combined with the fact of two engines working together as a pair with their cranks at right angles, causes such uniformity in the flow of the blast that no regulator of any lind is needed; indeed the variation is hardly perceptible in a mercury gauge placed on a very short length of main, whereas the variation on the ordinary plan is very considerable, as shown by the indications in the diagram Fig. 7 , taken from an ordinary eugine, which may be compared with Fig. 8, taken from the pair of small engines. The pair of engines are arranged to blow 3600 cubic ft. per minute, and are speeded to 80 revolutions per minute, which with $2 \mathrm{ft} .6$ in. stroke makes 400 feet per minute, and this they do with the greatest ease and efficiency, owing to the exact manner in which the lap and lead and area of passages, \&c., are proportioned; but the author does not wish it to be supposed that he recommends a higher speed, or at all events a much higher speed,for although we have the example of locomotive engines before us cvery day working at higher speeds, we also know something of the cost of repairs of locomotives working at high speeds, and it is evident that what an iron master wants is a good serviceable engine that will blow steadily on day and night without repairs and stoppages; in addition to these first requisites there are two other advantages which it is certain are attained by this construction of blast engine, namely, first, great regularity of pressure in the blast, and secondly, greatly reduced first cost of engine and of foundations.

The Chamman said the engines appeared remarkably compact and small for blowing a furnace, and the uniformity of pressure 
obtained by them would be an important advantage. There had been a variety of plans advocated for obtaining a blast suitable to the different requirements of the cupola and the blast furnace; and he remembered that at a recent meeting of the British Association the subject had been discussed, and it had been proposed to use the fan for the blast furnace. He understood that there was a furnace near Chesterfield blown by a fan, but he did not know the particulars of its application.

Mr. SAMUel Lloyd, jun., believed the great difficulty in using the fan for blowing a blast furnace was to get pressure enough for that purpose, and he understood it had been found impracticable to obtain sufficient pressure of blast from the fan to force air enough into the furnace.

The Chairman observed that it had been argued on the other hand in favour of the fan, that the operations of the blast furnace depended on the quantity of air delivered into the furnace, rather than upon the pressure at which it was delivered, and this view of the question was, he believed, more generally entertained now than previously, but he had not heard the results of the practical trial of the fan for blast furnaces. He mentioned that a number of blowing machines of different constructions were to be seen at the French Exhibition, showing a great amount of skill and ingenuity; in one of them, the general plan of the machine was much the same as that described in the paper, having an upright cylinder like that shown in the drawing, with a very large flat slide valve working on each side, for the admission and discharge of the air.

Mr. CowPER observed that there was a great practical advantage in the engines described in the paper, from the air valve having no side pressure whatever upon it, as it was a circular valve entirely surrounding the blast cylinder, and consequently was perfectly in balance; and being guided very steadily, by fitting the cylinder at top and bottom, its motion was very smooth, and the wear upon it would be very slight.

Mr. Samuel Lloyd. jun., enquired whether the small engines were to be worked with high-pressure or low-pressure steam ; in the use of high-pressure blowing engines he had known some difficulty to be 
experienced in keeping up a regular blast, owing to the steam pressure being occasionally let down in the night; but a lowpressure engine was not liable to that objection. In the present case of a pair of engines blowing together, one might be worked high-pressure and the other condensing with the same steam, and saving a large proportion of the fuel.

Mr. CowPER replied that the engines had been designed specially for lightness, to meet the peculiarity of the situation for which they were intended, and they had therefore been made non-condensing, cutting off at half stroke, with $50 \mathrm{lbs}$. steam; but wherever the circumstances admitted of it, he would certainly make high-pressure expansive and condensing engines, so that great economy of fuel would be obtained.

Mr. SAMUEL Lloxd, jun, remarked that in the case of a single blowing engine the use of a fly-wheel was objected to, as it was then found that the blast was less steady than without the fly-wheel.

Mr. Cowper observed that this must necessarily be the case with a single engine, as the fly-wheel, by making the crank shaft revolve uniformly, caused the motion of the piston to be faster at the middle than at the ends of the stroke; but in the ordinary single engines without a fly-wheel, the motion of the piston was regulated by the resistance of the air, and consequently it remained much more uniform throughout the stroke, causing less fluctuation in the supply of air to the main. A fly-wheel was only applicable when two blowing engines were coupled at right angles to one another, but even then the full advantage of the engines being coupled could not be obtained except by a quick-stroke small engine, such as those described in the paper, where the intervals between the successive discharges of air into the main became so small (amounting to less than a quarter of a second) that no appreciable fiuctuation of pressure was produced, although the ordinary regulator or reservoir was entirely dispensed with.

The Chatrman observed that this regularity of the blast was a great adrantage, and gave an important superiority over the ordinary engines; the same advantage would apply still more completely to the fan blast, if it were found capable of producing sufficient pressure, and he should be glad to know the exact particulars of its application to blowing furnaces. 
Mr. SAmuli Lroyd, jun., remarked that one difficulty in applying the fan to blowing furnaces would arise from the circumstance, that it was sometimes requisite to employ a higher pressure and smaller tuyeres for a time, in order to clear the furnace when it had got out of order ; this could be readily effected with blowing cylinders by increasing the steam pressure when required for that purpose.

Mr. COWPER said that a different treatment was requisite for blowing a blast furnace and for a cupola ; for blowing a cupola experience had led him to prefer the fan to a cylinder blowing engine; he was aware that a heavier pressure had been advocated for the cupola, but he had found a large quantity of air blown through 10 inch tuyeres better for that purpose than a higher pressure with smaller tuyeres; but for blowing a blast furnace, he did not think the fan would give pressure onough to force air into the centre of the furnace at all. He remembered that a plan had been suggested by Mr. Buckle, at a former meeting of the Institution, for increasing the pressure of the fan blast, by using two or three fans, one blowing into the other, making them all push together, so as to increase the pressure successively, the last one only communicating with the furnace.

Mr. SAMPson Llord remarked that the great improvement effected in the last few years in the quantity of iron obtained from blast furnaces was mainly attributable to the increased quantity of air blown into them: a few years ago, 40 tons of iron per week was the general yield of a furnace, but this was gradually increased up to 80 and 100 tons, and now 150 to 200 tons per week might be obtained from a single furnace, which was as much as was given by four or five furnaces formerly. He thought it would be impossible to force in the supply of air necessary to obtain this quantity of iron by means of the fan, and he understood it had been given up at the furnaces near Chesterfield that had been referred to.

Mr. CLIFT enquired what was the power of the pair of blowing engines described in the paper, and the quantity of air they would deliver.

Mr. Cowper replied that they were capable of working up to 34 indicated horse power each, and delivering together 3600 cubic feet of air per minute, at a pressure of 4 lbs. per square inch. 
Mr. CLIFT remarked that it had been proposed to use Jones's Gas Exhauster as a blowing engine, using four of them together, working one into another, in order to get sufficient power; he was not aware that they had been so used in this country, but he believed they were employed to a considerable extent in Sweden, where they were driven by water. This machine was very simple and portable in construction, and he had found it work very satisfactorily in discharging gas; from an experiment that had been made with the exhauster, it appeared that a steam engine of 5 nominal horse-power would force 80,000 cubic feet per hour of coal gas, or about 1300 feet per minute.

Mr. CowPen said that he had obtained a pressure of 10 to 15 inches of water, or about $\frac{1}{2} \mathrm{lb}$.. per square inch, with a large fan blowing a cupola with two 10 inch tuyeres; but that $7 \frac{1}{2}$ inches (or about $\frac{1}{1}$ lb. per square inch) was what he had generally adopted for cupolas and smiths' fires.

Mr. W. A. ADAMs observed that he had heard of a fan at Messrs. Cubitt's works, in London, running, he believed, at 2000 revolutions per minute, by which a considerably higher pressure than usual was obtained. A great pressure might be obtained by using three such fans combined, the one fan blowing into the aperture of the other; this plan had been tried by Mr. F.J. Bramwell, and found to answer, the pressure indicated by the last fan being nearly three times that of each separate fan.

Mr. Henry Maddstay said he had not seen the fan at Messrs. Cubitt's, but understood that a pressure of 16 inches of water was obtained with it; it was. a Lloyd's silent fan, 3 feet diameter, and worked quite silently.

The Chairman observed that Schiele's fan, which was much used in Manchester, was also a noiseless fan; it was worked at a very high speed, making 2000 to 3000 revolutions per minute.

$\mathrm{He}$ proposed a vote of thanks to Mr. Cowper for his paper, which was passed. 
The following Paper, by Mr. W. Bridges Adams, of London, was then read :- 


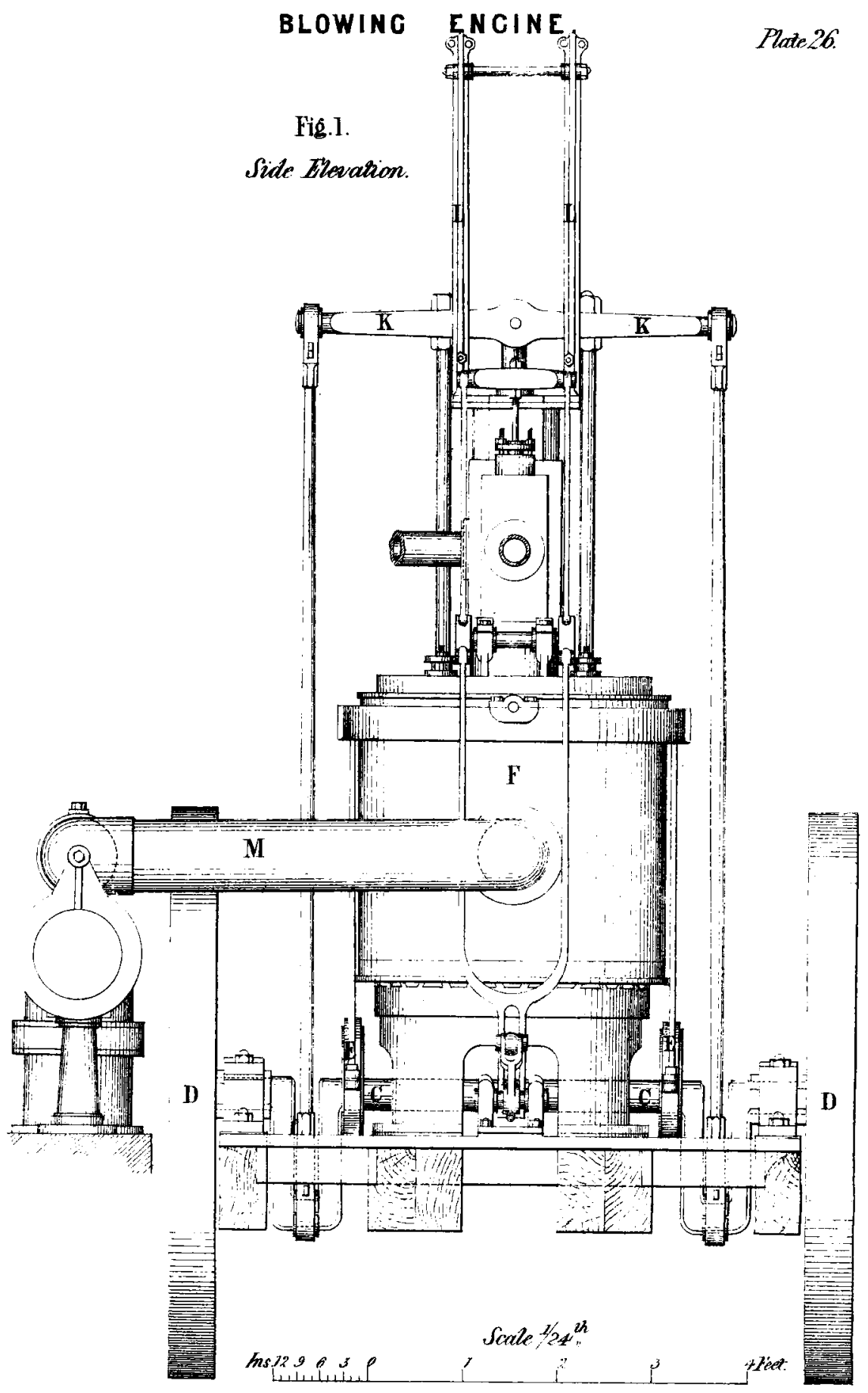

(Amceedingr Downloaded from pme.sagepub.com at MCGGILL UNIVERSITY LIBRARY on June 8, 2016 
BLOWING ENGINE.

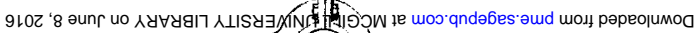

Plate 2Y.

Fig 2 .

Fertical Section.

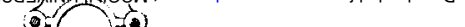


BLOWING ENGINE.

Fig.3. Plan.

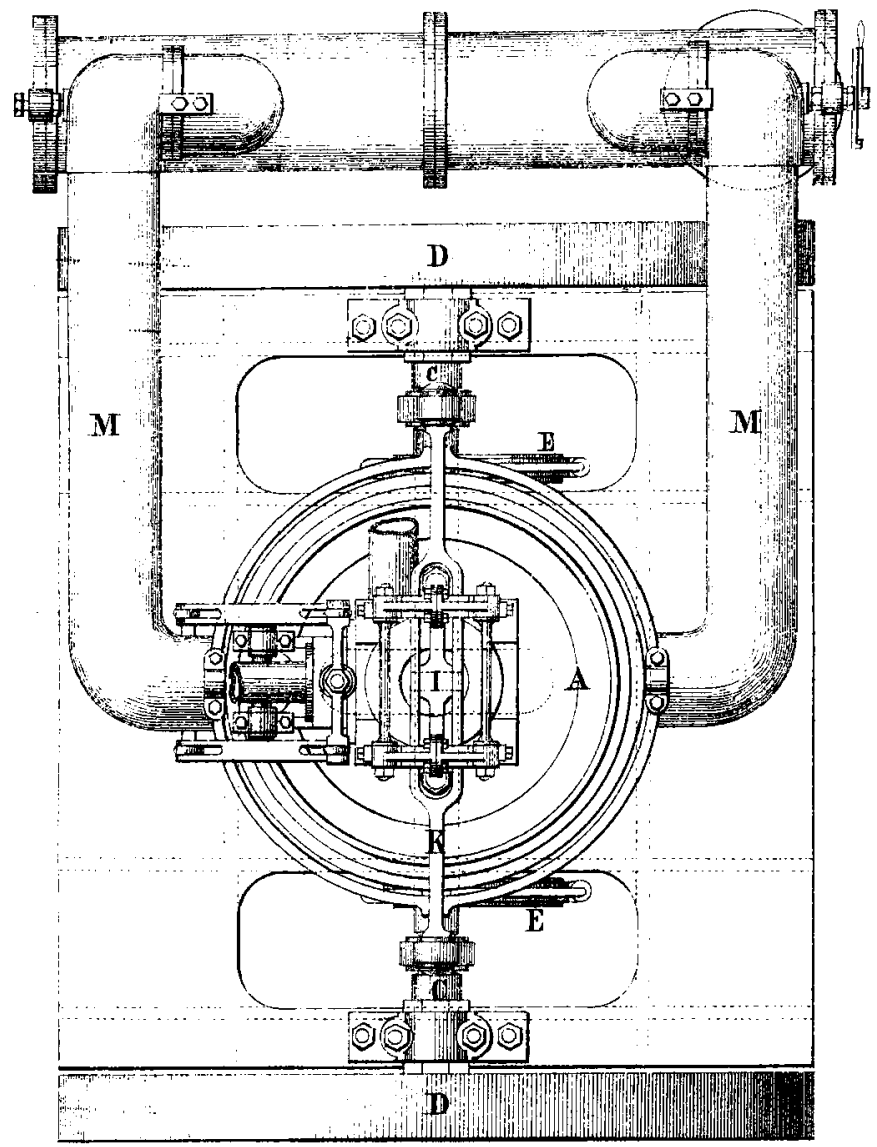

Fig.4.

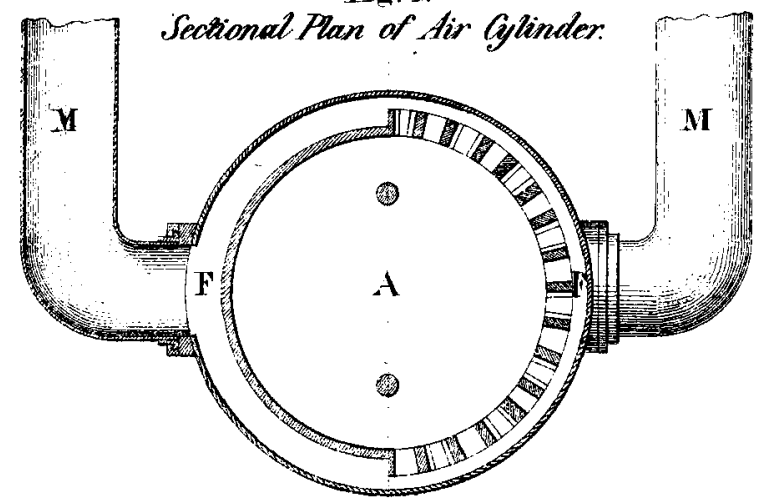



Feet. 
Fig.5.

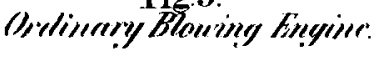

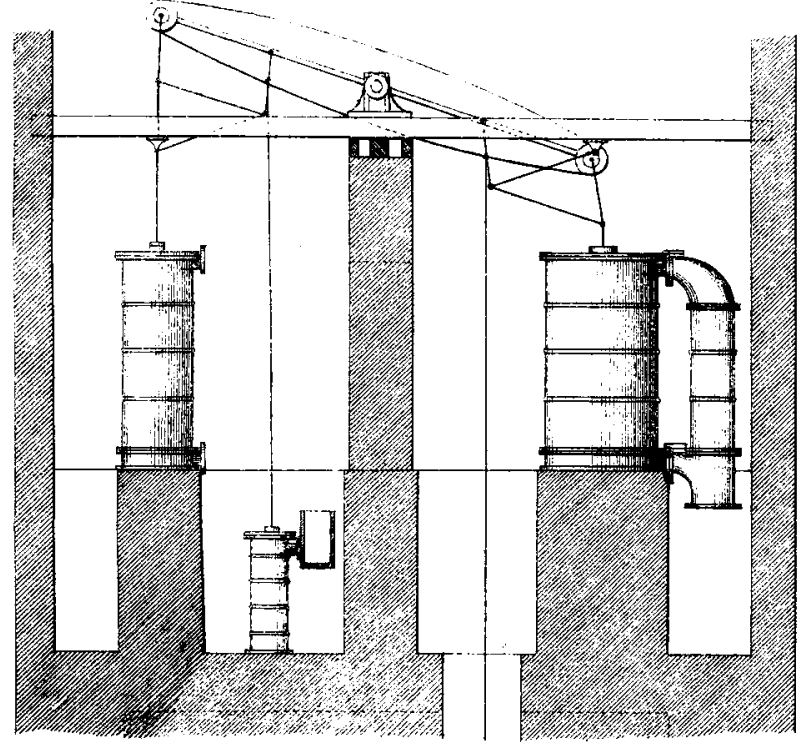

Fig. 6.

Jine

Blomeing

Enpine.



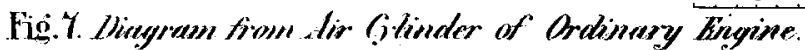



हैं

Fig.8. Lingram from . Air Cylinder of tow Lngine.
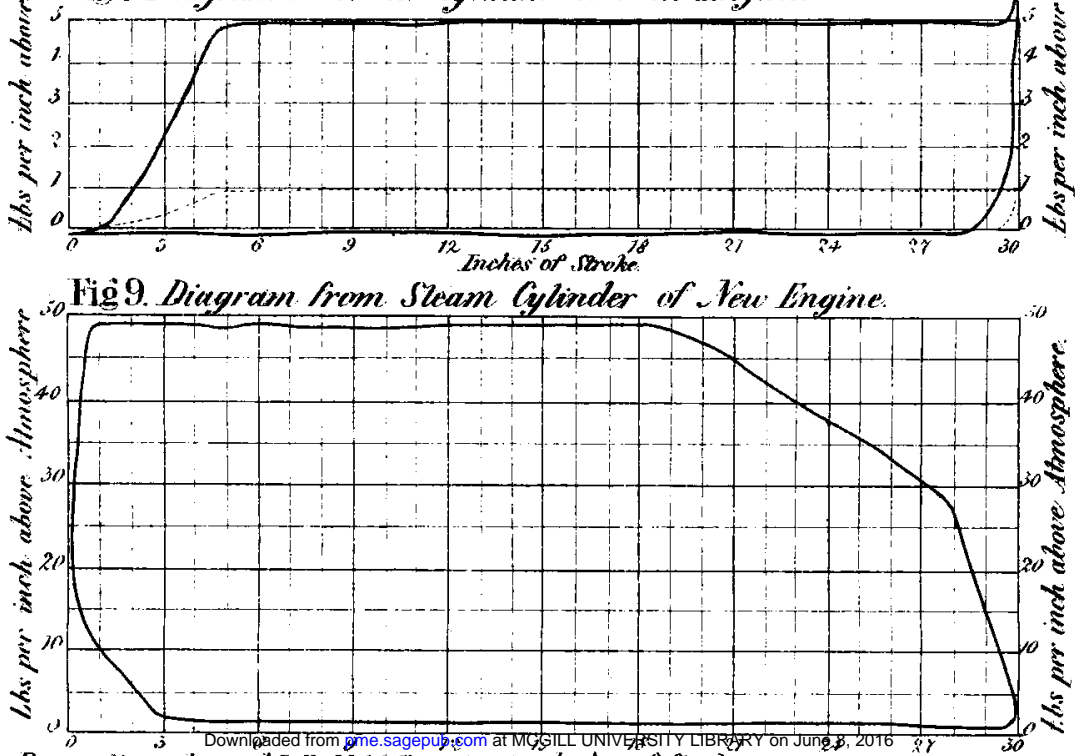

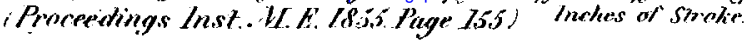

